\title{
Comparative Study Between Direct Vector Control and Fuzzy Sliding Mode Controller in Three-Level Space Vector Modulation Inverter of Reactive and Active Power Command of DFIG-Based Wind Turbine Systems
}

\author{
Habib BENBOUHENNI \\ National Polytechnique School of Oran Maurice Audin, Oran, Algeria \\ (habib0264@gmail.com) \\ ${ }^{\ddagger}$ Corresponding Author; Habib Benbouhenni, BP: 50B Ouled Fares Chlef, Algeria, Tel: +213663956329, \\ habib0264@gmail.com
}

Received: 25.11.2018 Accepted:18.12.2018

\begin{abstract}
This article deals with the dynamic simulation of a directly driven wind turbine (WT) with a full-scale converter as the interface to the grid. Using the doubly fed induction Generator (DFIG), the system is controlled by two command strategies. I the first step, we have considered the direct vector control (DVC) strategy with three-level space vector modulation (SVM) and in the second one, we have applied the fuzzy sliding mode control (FSMC) strategy with three-level SVM inverter. Simulation results investigated good performances of both proposed non-linear approaches.
\end{abstract}

Keywords Doubly fed induction generator, wind turbine, direct vector control, fuzzy sliding mode control, and three-level space vector modulation.

\section{Introduction}

Traditionally, wind turbine systems (WTSs) based on the doubly fed induction generator (DFIG) dominated the wind energy generations due to the outstanding advantages, including small converters rating around $30 \%$ of the generator rating, lower converter cost. However, the DFIGbased WTS are mainly installed in remote and rural areas [1]. Various command schemes have been proposed for studying the behaviour of DFIG based WTSs during normal operation. Most existing structures widely used a traditional vector command (VC) based on stator flux orientation or a stator voltage orientation. In [2] VC commands is the most popular technique used in the doubly fed induction generator-based WTSs. On the other hand, the VC command is a simple command scheme and easy implement. The VC command needs accurate values of DFIG parameters and rotor speed. This command gives more total harmonic distortion (THD) of rotor current, powers ripples, stator flux and electromagnetic torque.

The conventional command strategy of doubly fed induction generator-based WTS is the indirect vector control (IVC) and direct vector control (DVC), where the reactive and active powers of doubly fed induction generator are controlled using current controller blocks [3]. In this article, we propose to command stator active and reactive powers of a DFIG by using a DVC command. This command is a simple command scheme and easy to implement. However, this command gives more rotor current ripple, stator flux ripple and electromagnetic torque ripple.

For robust and high-performance DVC, a sliding mode controller (SMC) was proposed to command stator active power and stator reactive power of a doubly fed induction generator $[4,5]$. This strategy was proposed by Utkin in 1974 [6]. This technique is one of the nonlinear strategies. It is a particular operation mode of variable structure command systems [7]. Since the robustness is the best advantage of the SMC technique. However, the SMC strategy has a major 
inconvenience which the chattering effect is created by the discontinuous part of the command. In order to resolve this problem, various adjustments to the usual command law have been discussed. The approach based on the boundary layer is applied in almost all cases. Another efficiency solution consists to substitute the discontinuous command signal by fuzzy logic (FL) one has also been used recently in some research works [8-9]. FL controller and SMC technique are combined to command DFIG [10].

Since the space vector modulation (SVM) technique is widely used in command AC machine. This strategy is based on the representation of the voltage vector in a rotating complex frame [11]. However, this strategy is detailed in [12-14]. In addition, this strategy is difficult to implement. To overcome this disadvantages an SVM technique is proposed based on calculating of maximum and minimum of three-phase voltages. The proposed SVM technique is a simple scheme and easy to implement. In this paper, we propose a new SVM technique for three-level inverter based on calculating the min and max of three-phase voltages.

In our paper, two different command schemes will be compared with each other. These schemes are DVC command using three-level SVM strategy and FSMC using three-level SVM inverter. The proposed commands schemes are described clearly and simulation results are reported to demonstrate its effectiveness. The used command schemes are implemented in Matlab software.

\section{Three-level space vector modulation}

The SVM strategy is a kind of a modulation scheme with a superior performance compared to classical pulse width modulation (PWM) and third harmonic injection PWM (THIPWM) for the inverter-command applications. In the traditional SVM technique, it is always necessary to perform many trigonometric operations and coordinate matrix transformations to determine the sector position of the equivalent voltage space vector [15]. For simple and high-performance SVM, a new SVM technique was studied in the literature [16, 17]. This proposed SVM is a simple scheme, easy to implement and give more THD value of stator current of a DFIG-based WTSs.

In this article, we proposed a new space vector modulation for the three-level inverter. These proposed modulations based on calculating of maximum (max) and minimum (min) of three voltages. The advantages of the proposed SVM strategy is not needed to calculate the sector and angle, easy to implement and gives a strong performance for the real-time feedback command compared with classical SVM strategy. Fig. 1 shows the principle of the SVM technique of three-level inverter.

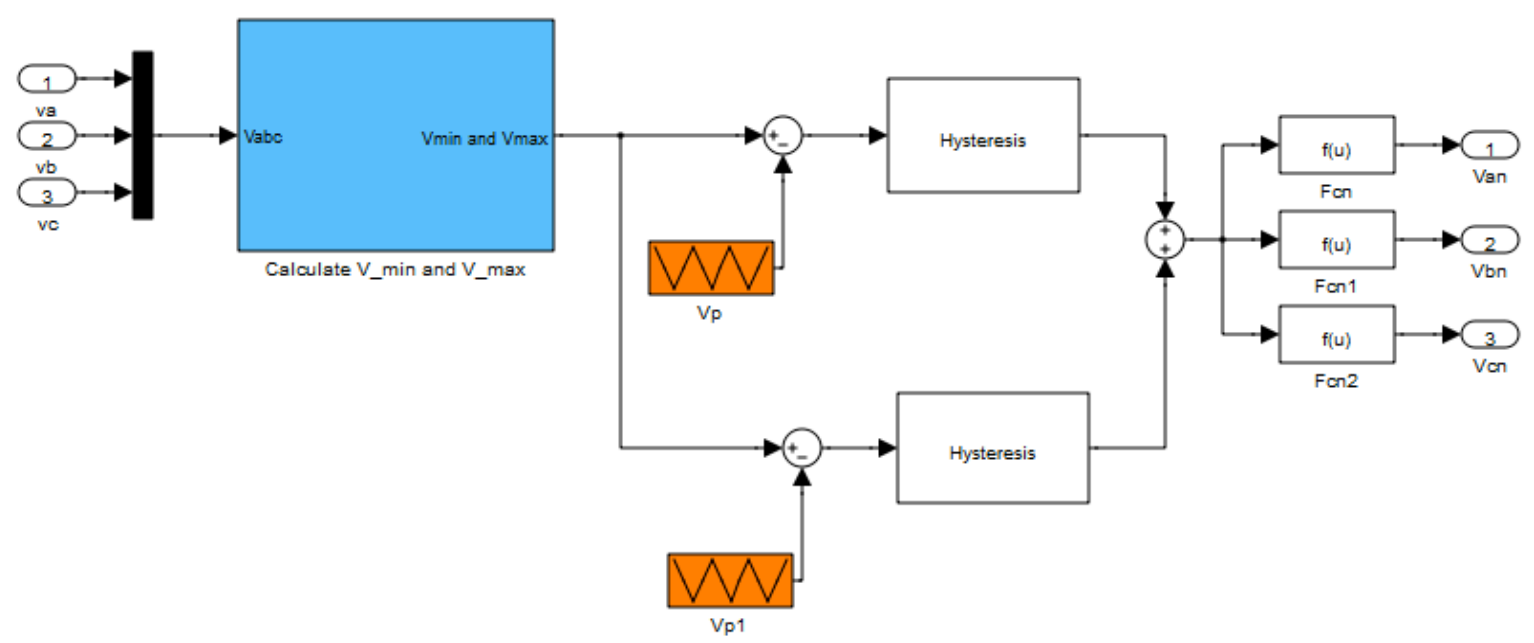

Fig. 1. Three-level SVM strategy.

Fig. 2 represents the block diagram of the hysteresis comparators for five-level inverter.

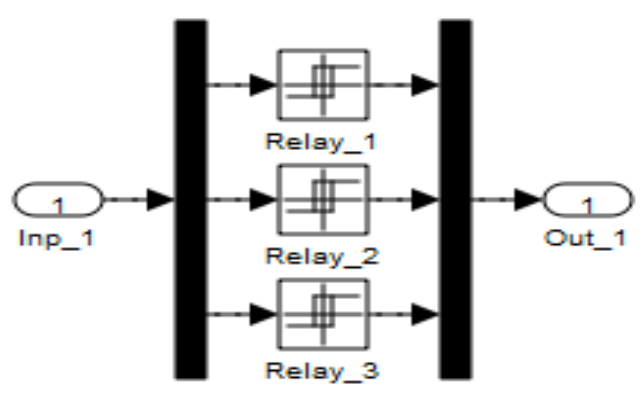

\section{The DFIG model}

The traditional electrical equations of the doubly fed induction generator in the Park frame are written as follows $[18,19]$ :

$$
\left\{\begin{array}{l}
\psi_{d s}=L_{s} I_{d s}+M I_{d r} \\
\psi_{q s}=L_{s} I_{q s}+M I_{q r} \\
\psi_{d r}=L_{r} I_{d r}+M I_{d s} \\
\psi_{q r}=L_{r} I_{q r}+M I_{q s}
\end{array}\right.
$$

Fig. 2. Block diagram of the hysteresis comparators. 


$$
\begin{aligned}
& \left\{\begin{array}{l}
\mathrm{v}_{\mathrm{ds}}=\mathrm{R}_{\mathrm{s}} \mathrm{I}_{\mathrm{ds}}+\frac{\mathrm{d}}{\mathrm{dt}} \psi_{\mathrm{ds}}-\omega_{\mathrm{s}} \psi_{\mathrm{qs}} \\
\mathrm{V}_{\mathrm{qs}}=\mathrm{R}_{\mathrm{s}} \mathrm{I}_{\mathrm{qs}}+\frac{\mathrm{d}}{\mathrm{dt}} \psi_{\mathrm{qs}}+\omega_{\mathrm{s}} \psi_{\mathrm{ds}} \\
\mathrm{V}_{\mathrm{dr}}=\mathrm{R}_{\mathrm{r}} \mathrm{I}_{\mathrm{dr}}+\frac{\mathrm{d}}{\mathrm{dt}} \psi_{\mathrm{dr}}-\omega_{\mathrm{r}} \psi_{\mathrm{qr}} \\
\mathrm{V}_{\mathrm{qr}}=\mathrm{R}_{\mathrm{r}} \mathrm{I}_{\mathrm{qr}}+\frac{\mathrm{d}}{\mathrm{dt}} \psi_{\mathrm{qr}}+\omega_{\mathrm{r}} \psi_{\mathrm{dr}}
\end{array}\right. \\
& \left\{\begin{array}{l}
\psi_{d s}=L_{s} I_{d s}+M I_{d r} \\
\psi_{q s}=L_{s} I_{q s}+M I_{q r} \\
\psi_{d r}=L_{r} I_{d r}+M I_{d s} \\
\psi_{q r}=L_{r} I_{q r}+M I_{q s}
\end{array}\right.
\end{aligned}
$$

The reactive and active powers at the stator can be expressed as:

$$
\left\{\begin{array}{l}
P_{S}=\frac{3}{2}\left(V_{d s} I_{d s}+V_{q s} I_{q s}\right) \\
Q_{S}=\frac{3}{2}\left(V_{q s} I_{d s}-V_{d s} I_{q s}\right)
\end{array}\right.
$$

The torque is expressed as:

$$
T_{e}=T_{r}+J \cdot \frac{d \Omega}{d t}+f \cdot \Omega
$$

$V_{d r}, V_{q r}, V_{q s}$ and $V_{d s}$, are the two-phase rotor and stator voltages, $I_{d r}, I_{q r}, I_{d s}$ and $I_{q s}$, are the two-phase rotor and stator currents, $\psi_{d r}, \psi_{q r}, \psi_{d s}$ and $\psi_{q s}$, are the two-phase rotor and stator fluxes, $L_{r}, L_{s}$ and $M$ are respectively the inductance own rotor, stator, and the mutual inductance between two coils, $R_{r}$ and $R_{s}$ are respectively the resistances of the rotor and stator windings.

$T_{r}$ is the load torque, $\mathrm{T}_{\mathrm{e}}$ is the electromagnetic torque, $\Omega$ is the mechanical rotor speed, $J$ is the inertia, $f$ is the viscous friction coefficient and $p$ is the number of pole pairs.

$\mathrm{P}_{\mathrm{s}}$ is the active power, $\mathrm{Q}_{\mathrm{s}}$ is the stator reactive power.

\section{Command techniques of the DFIG}

In this part, comparison of doubly fed induction generator performances using different command schemes: direct vector control (DVC) with three-level SVM (3L-SVM) and fuzzy sliding mode controller (FSMC) with 3L-SVM.

\subsection{Direct vector control (DVC)}

The principle of DVC command is detailed in [20, 21]. This command is a simple scheme and easy to implement. However, the major disadvantage of the DVC command is the ripple powers and harmonic distortion of stator current. To eliminate these drawbacks, a DVC-SVM is proposed in this article. The structure of DVC-SVM of a doubly fed induction generator is shown in Fig. 3. However, the internal structure of DVC is shown in Fig. 4.

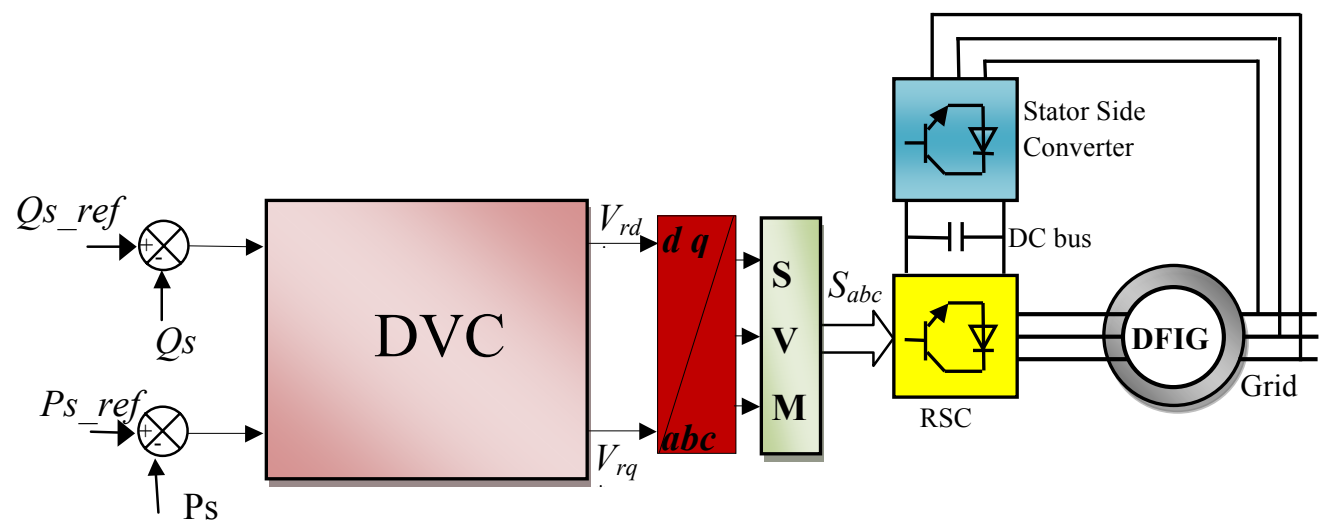

Fig. 3. DVC command with SVM inverter.

\subsection{Fuzzy sliding mode controller (FSMC)}

In command systems, fuzzy sliding mode control (FSMC) is a modification of an SMC strategy. This strategy minimizes more and more the chattering phenomenon.
On the other hand, this strategy reduces the powers ripples and the THD value of rotor current for DFIG-based WTSs. In this strategy the switching controller term sat $(\mathrm{S}(\mathrm{x}))$, has been replaced by a fuzzy command input as given below. 


$$
V_{d q}^{c o m}=V_{d q}^{e q}+V_{d q}^{F u z y}
$$

The proposed FSMC command, which is designed to command the stator reactive and active powers of the doubly fed induction generator, is shown in Fig. 5.
For the two proposed FSMC in Fig. 5, the universes of discourses are first partitioned into the 7 linguistic variables $\mathrm{NB}, \mathrm{NM}, \mathrm{NS}$, EZ, PS, PM, PB, triangular membership functions are chosen to represent the linguistic variables and fuzzy singletons for the outputs are used. The fuzzy rules that produce these command actions are reported in Table 1.

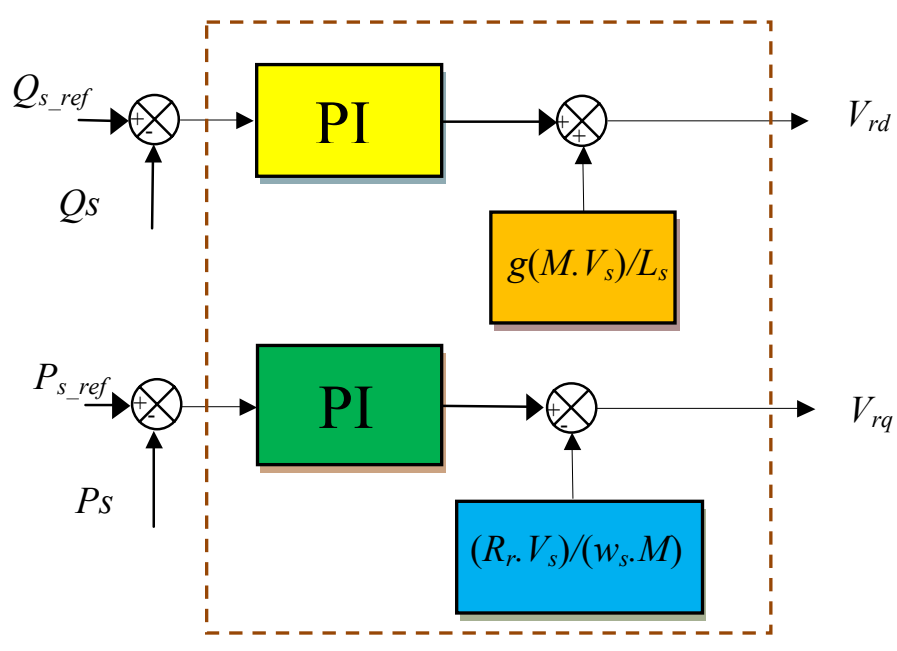

Fig. 4. Structure of DVC command scheme.

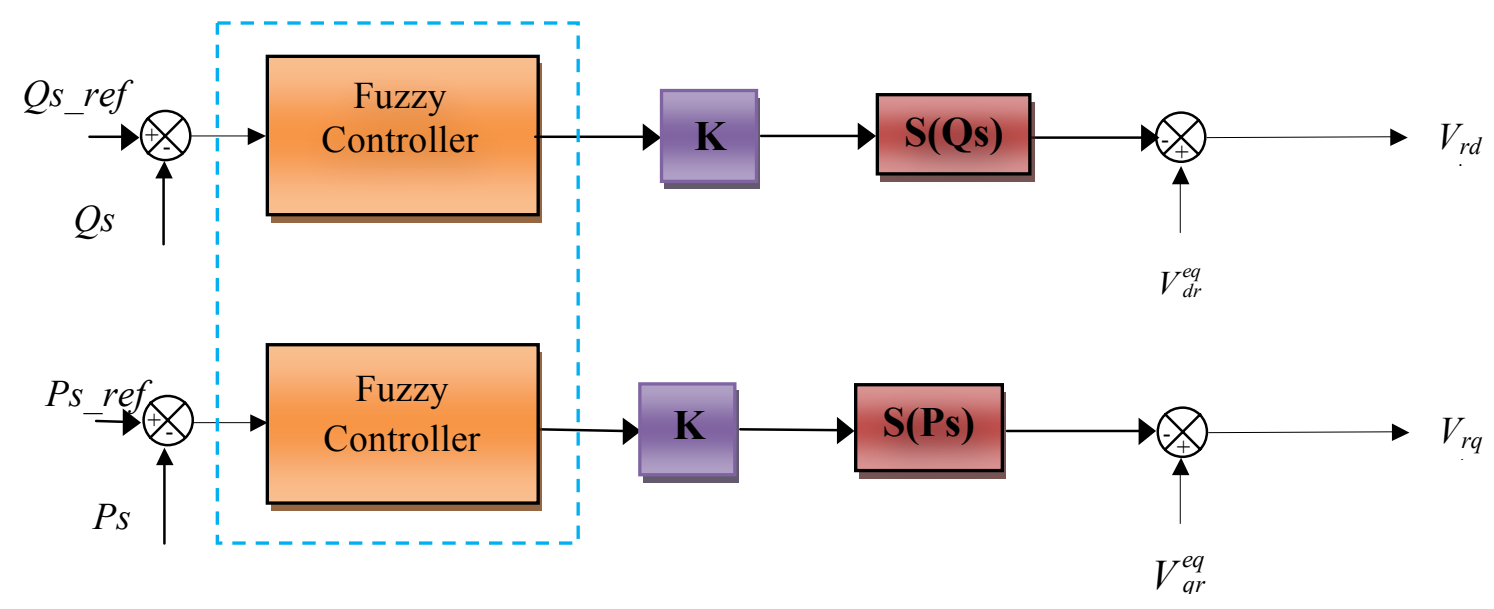

Fig. 5. Bloc diagram of the DFIG command with FSMC.

Table 1. The fuzzy logic rules of hysteresis comparators.

\begin{tabular}{|l|l|l|l|l|l|l|l|}
\hline \multicolumn{1}{|c|}{$\mathbf{e}$} & NB & NM & NS & EZ & PS & PM & PB \\
\cline { 1 - 6 } \multicolumn{1}{|c}{} & & & & & & & \\
\hline NB & NB & NB & NB & NB & NM & NS & EZ \\
\hline NM & NB & NB & NB & NM & NS & EZ & PS \\
\hline NS & NB & NB & NM & NS & EZ & PS & PM \\
\hline EZ & NB & NM & NS & EZ & PS & PM & PB \\
\hline PS & NM & NS & EZ & PS & PM & PB & PB \\
\hline PM & NS & EZ & PS & PM & PB & PB & PB \\
\hline PB & EZ & PS & PM & PB & PB & PB & PB \\
\hline
\end{tabular}

Table 2. Parameters of fuzzy controller

\begin{tabular}{|l|c|}
\hline Fis type & Mamdani \\
\hline And method & Min \\
\hline Or method & Max \\
\hline Implication & Min \\
\hline Aggregation & Max \\
\hline Defuzzification & Centroid \\
\hline
\end{tabular}

Table 2 shows the parameters of fuzzy controllers.

The membership function definition for the input variables and output membership is given by Fig. 6 . 
The structure of DVC-SVM of a doubly fed induction generator is shown in Fig. 7.
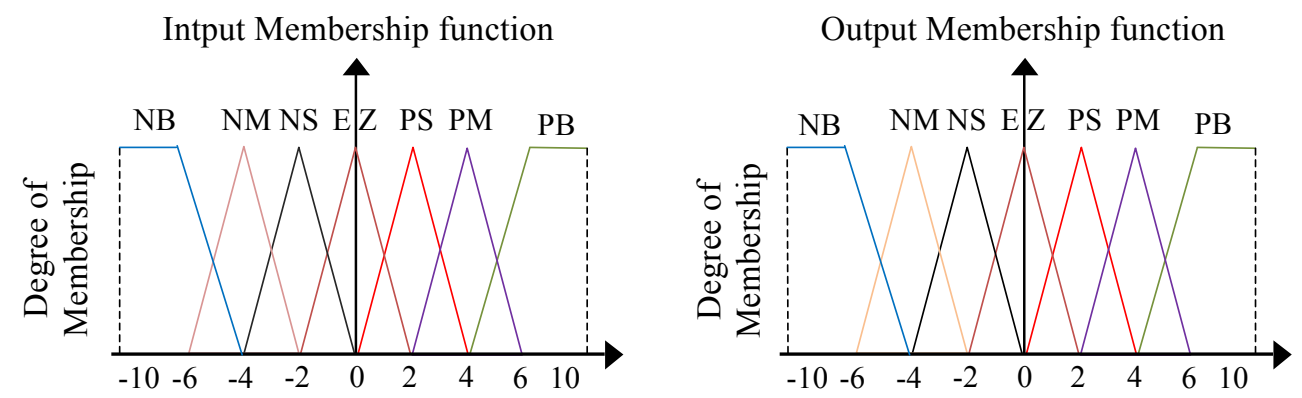

Fig. 6. Fuzzy sets and its memberships functions.

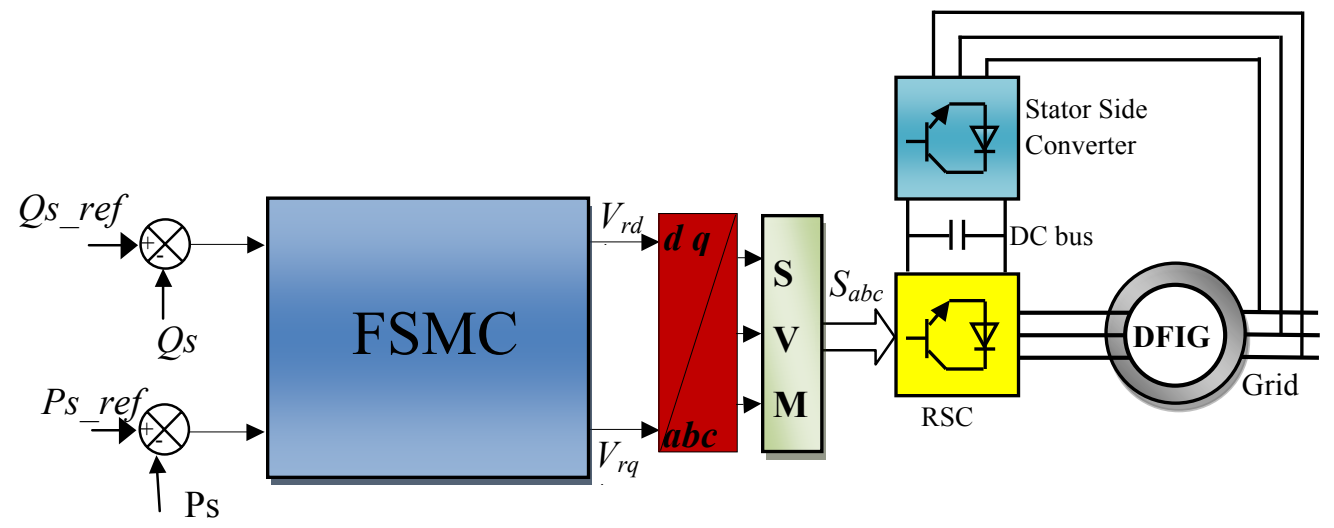

Fig. 7. FSMC command with SVM strategy.

\section{Simulation results}

In this part, simulations are carried out with a $1.5 \mathrm{MW}$ doubly fed induction generator attached to a $398 \mathrm{~V} / 50 \mathrm{~Hz}$ grid, using the Matlab/Simulink. Two command schemes, DVC-3L-SVM and FSMC-3L-SVM, are simulated and compared regarding powers ripples, reference tracking, rotor current harmonics distortion, and robustness against DFIG parameter variations.

The DFIG used in this case study is a $1.5 \mathrm{MW}, 380 / 696 \mathrm{~V}$, two poles, $50 \mathrm{~Hz}$; with the following parameters: $\mathrm{Rs}=$ $0.012 \Omega, \mathrm{Rr}=0.021 \Omega, \mathrm{Ls}=0.0137 \mathrm{H}, \mathrm{Lr}=0.0136 \mathrm{H}$ and $\mathrm{Lm}$ $=0.0135 \mathrm{H}$.

The system has the following mechanical parameters: $J=1000 \mathrm{~kg} \cdot \mathrm{m} 2, \mathrm{fr}=0.0024 \mathrm{Nm} . \mathrm{s} / \mathrm{rad}$.

\subsection{Reference tracking test (RTT)}

Figs. 14-15 show the harmonic spectrums of one phase rotor current of the $1.5 \mathrm{MW}$ DFIG for DVC-3L-SVM and FSMC-3L-SVM one respectively. Table 3 shows the comparative analysis of THD value. It can be clearly observed that the THD is minimized for FSMC-3L-SVM command $(\mathrm{THD}=0.37 \%$ ) when compared to DVC-3L-SVM $(\mathrm{THD}=3.04 \%)$.
Figs. 8-10 show the obtained simulation results. For the two command schemes, the stator active and stator reactive power tracks almost perfectly their references values. Moreover, the FSMC-3L-SVM command minimized the powers ripples and torque ripple compared to the DVC-3LSVM command (See Figs. 11-113).

Table 3. Comparative analysis of THD value (RTT)

\begin{tabular}{|c|c|c|}
\cline { 2 - 3 } \multicolumn{1}{c|}{} & \multicolumn{2}{c|}{ THD (\%) } \\
\cline { 2 - 3 } \multicolumn{1}{c|}{} & DVC-3L-SVM & FSMC-3L-SVM \\
\hline Rotor current & 3.04 & 0.37 \\
\hline
\end{tabular}

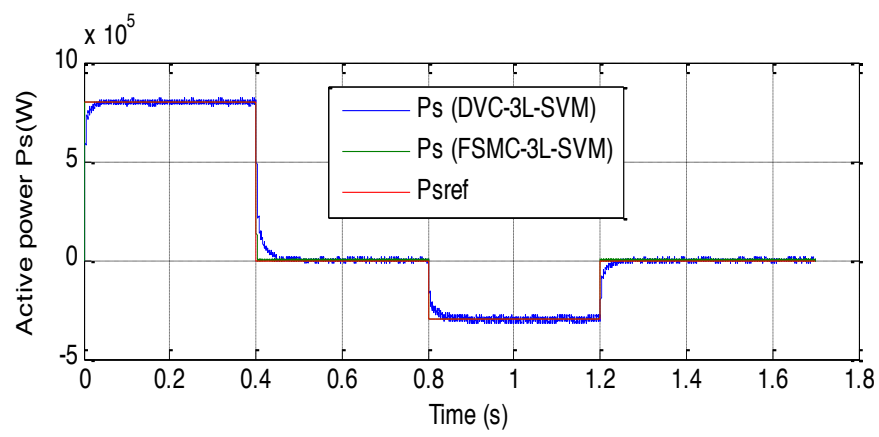

Fig. 8. Active power (RTT). 
INTERNATIONAL JOURNAL Of SMART GRID

Habib Benbouhenni, Vol.2, No.4, December 2018
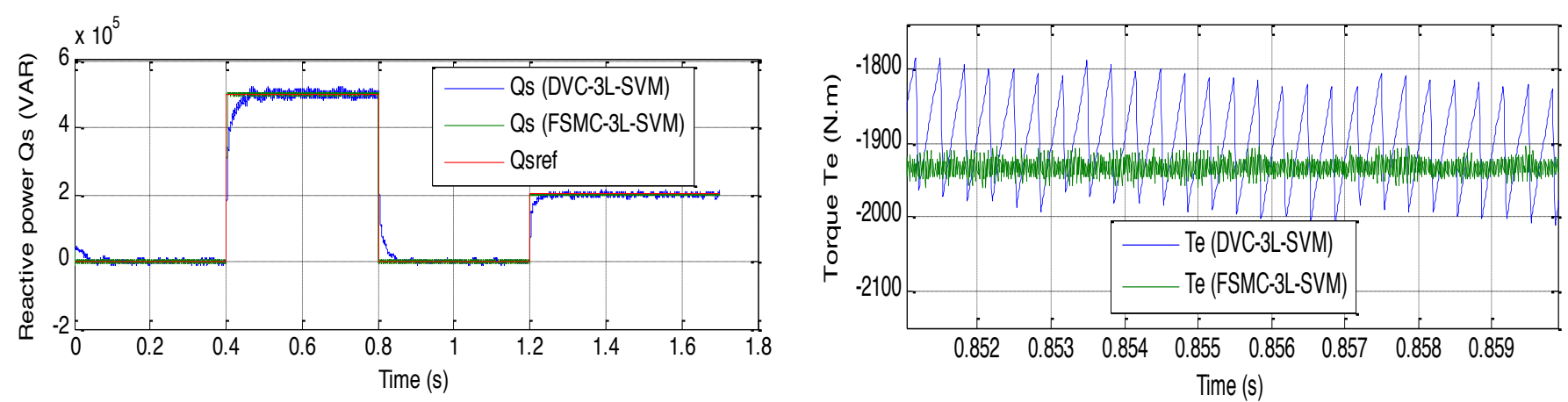

Fig. 9. Reactive power (RTT).

Fig. 13. Zoom in the torque (RTT).

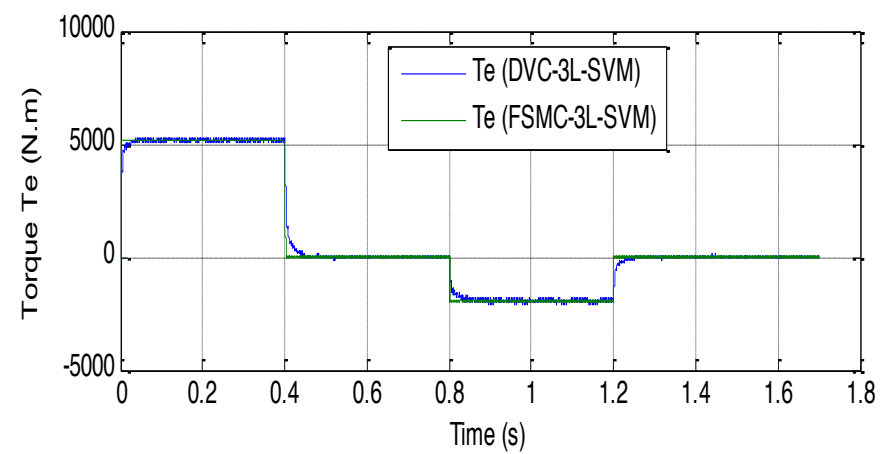

Fig. 10. Torque (RTT).

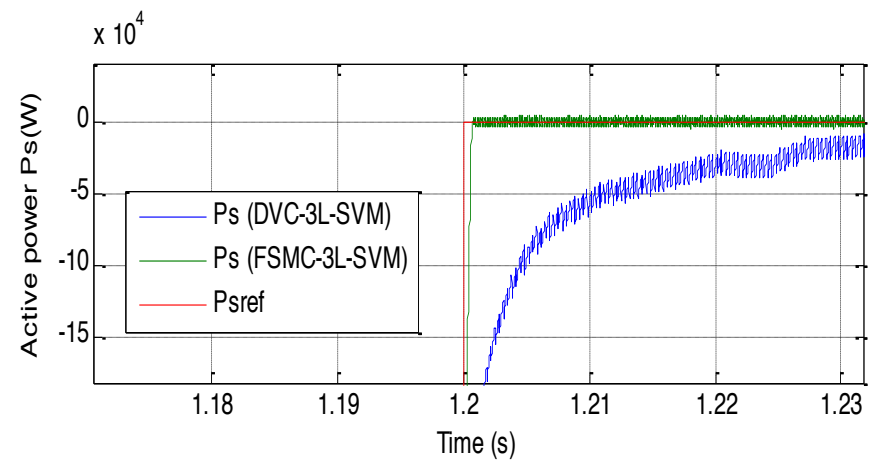

Fig. 11. Zoom in the active power (RTT).

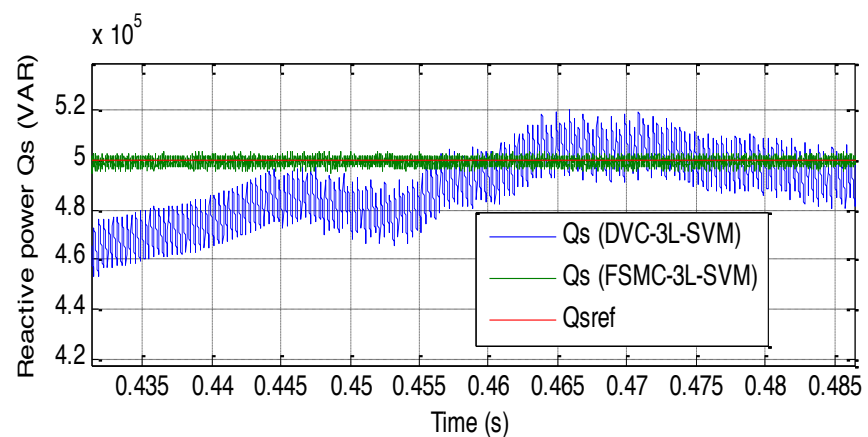

Fig. 14. THD of one phase rotor current for DVC-3L-SVM control (RTT).
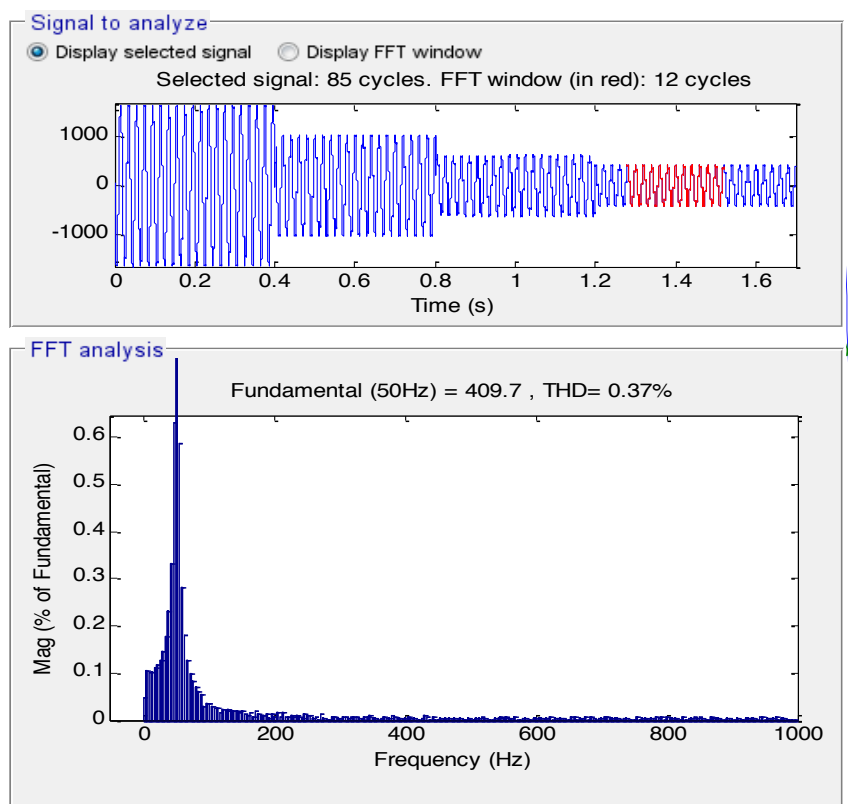

Fig. 12. Zoom in the reactive power (RTT).

Fig. 15. THD of one phase rotor current for FSMC-3L-SVM control (RTT). 


\subsection{Robustness test (RT)}

In this section, the nominal value of the $\mathrm{R}_{\mathrm{r}}$ and $R_{S}$ is multiplied by 2 , the values of inductances $L_{s}, \mathrm{M}$, and $\mathrm{L}_{\mathrm{r}}$ are multiplied by 0.5 . Simulation results are presented in Figs. 16-23. As it's shown by these Figures, these variations present a clear effect on the active power, stator reactive power, and electromagnetic torque curves and that the effect appears more important for the DVC-3L-SVM command compared to FSMC-3L-SVM command (See Figs. 19-21). On the other hand, the THD value of rotor current in the FSMC-3L-SVM has been minimized significantly (See Figs 22-23). Thus it can be concluded that the FSMC-3L-SVM command is more robust than the DVC-3L-SVM command.

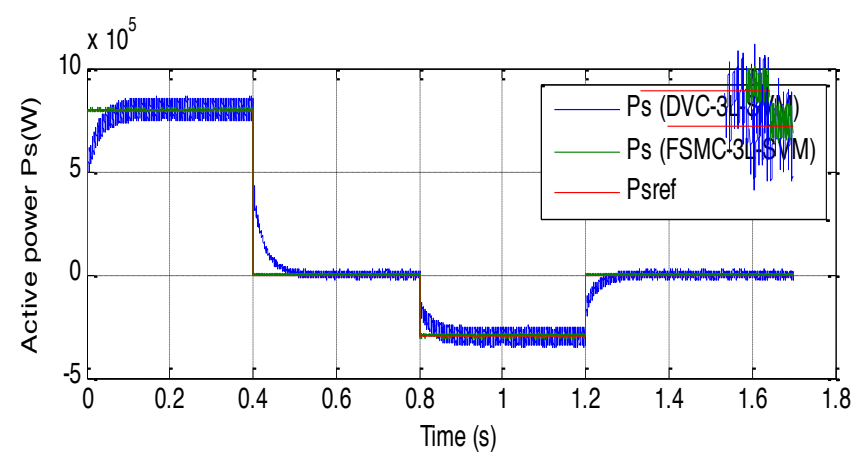

Fig. 16. Active power (RT).

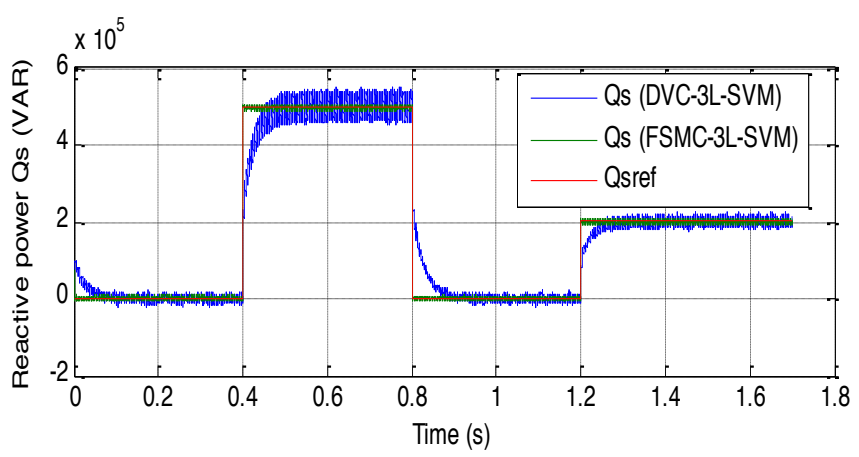

Fig. 17. Reactive power (RT).

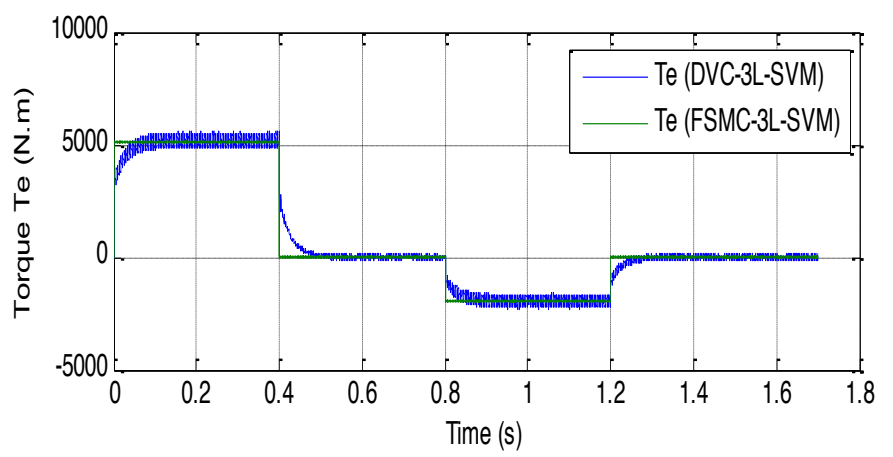

Fig. 18. Torque (RT).

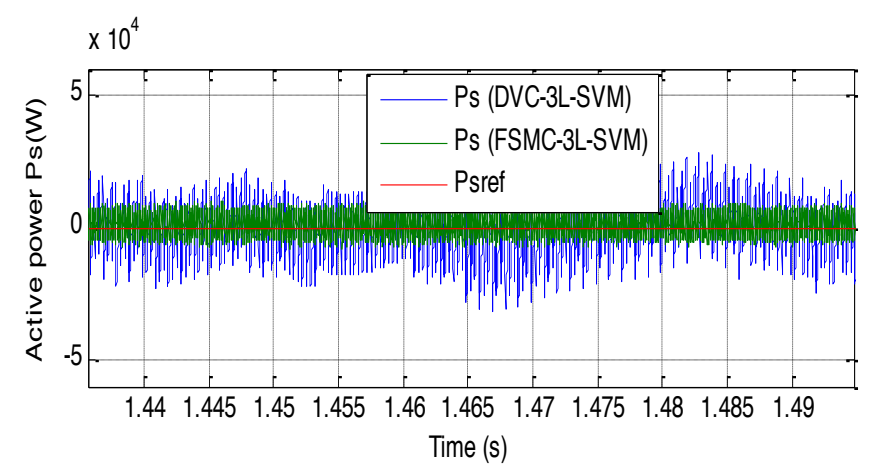

Fig. 19. Zoom in the active power (RT).

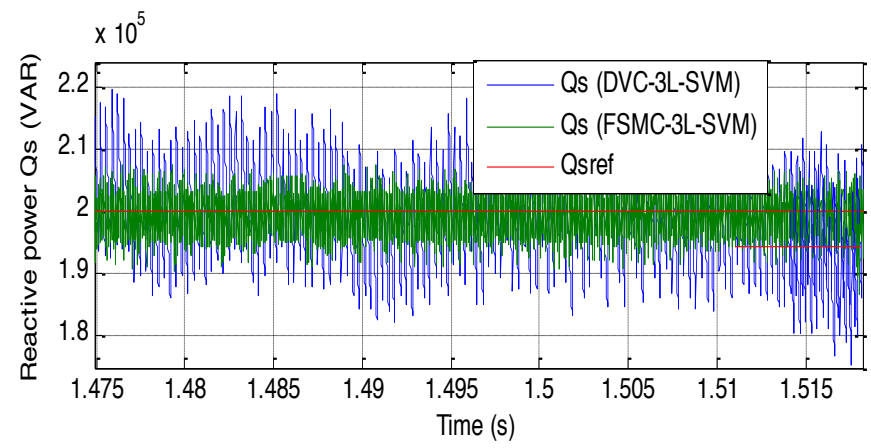

Fig. 20. Zoom in the reactive power (RT).

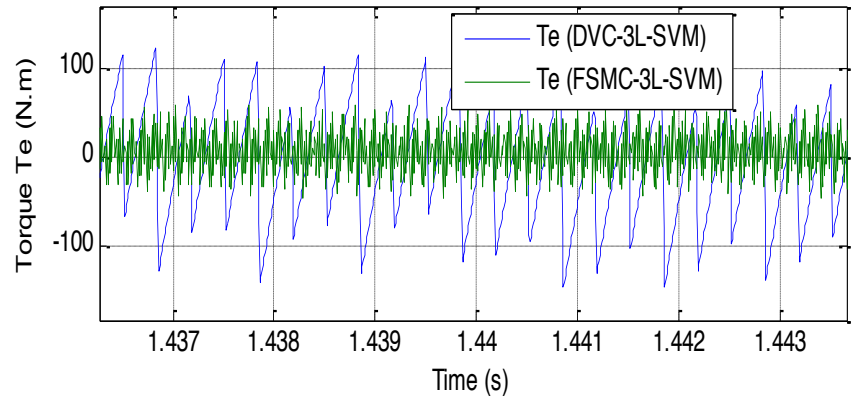

Fig. 21. Zoom in the torque (RT).
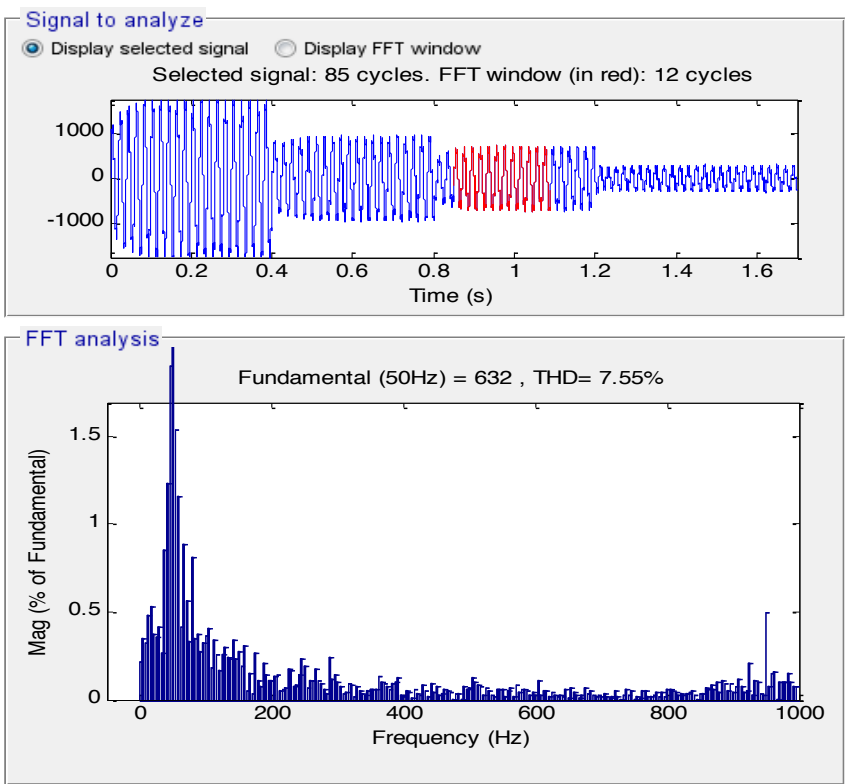

Fig. 22. THD of one phase rotor current for DVC-3L-SVM control (RT). 

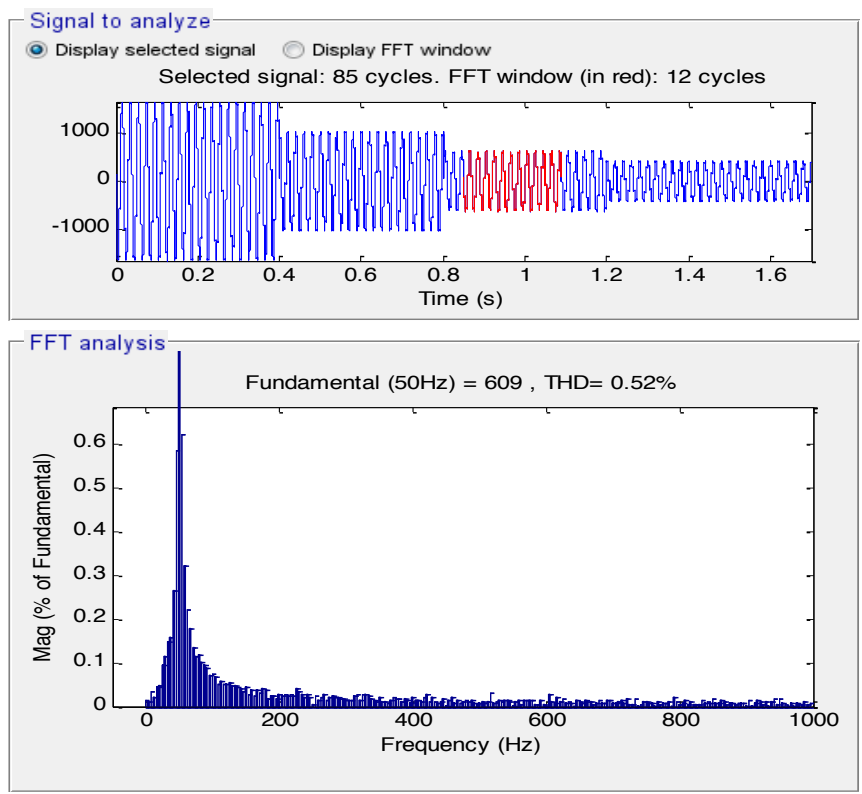

Fig. 23. THD of one phase rotor current for FSMC-3L-SVM control (RT).

\section{Conclusion}

This work presents simulation results of direct vector control and the fuzzy sliding mode control for reactive and stator active power command of a doubly fed induction generator, using the new modulation technique of space vector modulation inverter. With results obtained from the simulation, it was clear that for the similar operation conditions, the doubly fed induction generator reactive and active power command with FSMC command using threelevel SVM strategy had better performance than the DVC command with three-level and that is clear in the harmonic distortion of phase rotor current which the use of the FSMC with three-level SVM, it is minimizes of harmonics more and more than DVC with three-level SVM strategy.

\section{Reference}

[1] F. Amrane, A. Chaiba, « A novel direct power control for grid-connected doubly fed induction generator based on hybrid artificial intelligent control with space vector modulation, " Rev. Roum. Sci. Techn.Electrotechn. Et Energ, Vol. 61, No. 3, pp. 263-268, 2016.

[2] F. Amrane, A. Chaiba, B. D. Babes, S. Mekhilef, «Design and implementation of high performance field oriented control for grid-connected doubly fed induction generator via hysteresis rotor current controller, 》Rev. Roum. Sci. Techn.-Electrotechn. Et Energ, Vol. 61, No. 4, pp. 319-324, 2016.

[3] S. M. Tavakoli, M. A. Pourmina, M. R. Zolghadri, «Comparison between different DPC methods applied to DFIG wind turbines, » International Journal of Renewable Energy Research, Vol. 3, No. 2, pp. 446452, 2013.
[4] B. Hamane, M. L. Doumbia, M. Bouhamida, A. Draou, H. Chaoui, M. Benghanem, «Comparative study of PI, RST, Sliding mode and fuzzy supervisory controllers for DFIG based wind energy conversion system, ") International Journal of Renewable Energy Research, Vol. 5, No. 4, 2015, pp. 1174-1184.

[5] Z. Boudjema, A. Meroufel, Y. Djerriri, « Nonlinear control of a doubly fed induction generator for wind energy conversion, » Carpathian Journal of Electronic and Computer Engineering, Vol. 6, No. 1, 2013, pp. 28-35.

[6] Y. Bekakra, D. Ben Attous, "Comparison study between SVM and PWM inverter in sliding mode control of active and reactive power control of a DFIG for variable speed wind energy, » International Journal of Renewable Energy Research, Vol. 2, No. 3, 2012, pp. 471-476.

[7] B. Karima, A. Boukhelifa, « Output power control of a variable wind energy conversion system, » Rev. Roum. Sci. Techn.-Electrotechn. Et Energ, Vol. 62, No. 2, pp. 197-202, 2017.

[8] X. Yuan, Z. Chen, Y. Yuan, Y. Huang, « Design of fuzzy sliding mode controller for hydraulic turbine regulationg system via input state feedback linearization method, » Energy, Vol. 93, pp. 173-187, 2015.

[9] N. Ullah, W. Shaoping, M. I. Khattak, M. Shafi, «Fractional order adaptive fuzzy sliding mode controller for a position servo system subjected to aerodynamic loading and nonlinearities, » Aerosp Sci Technol, Vol. 43, pp. 381-387, 2015.

[10] B. Zinelaabidine, A. Meroufel, A. Amari, « Robust control of a doubly fed induction generator (DFIG) fed by a direct AC-AC converter, » Przegląd Elektrotechniczny, Vol. 12, 2012, pp. 213-221.

[11] O. Ouledali, A. Meroufel, P. Wira, S. Bentouba, «Torque and stator flux ripples minimization for direct torque control of PMSM by using space vector modulation, » Majlesi Journal of Electrical Engineering, Vol. 12, No. 3, pp.55-59, 2018.

[12] M. Gaballah, M. El-bardini, « Low cost digital signal generation for driving space vector PWM inverter, » Ain Shams Engineering Journal, Vol. 4, pp. 763-774, 2013.

[13] M. A. Moghadam, R. Noroozian, S. Jalilzadeh, «Modeling, simulation and control of matrix converter for variable speed wind turbine system, " Iranian Journal of Electrical \& Electronic Engineering, Vol. 11, No. 3, pp. 265-275, 2015.

[14] A. Chikhi, «Direct torque control of induction motor based on space vector modulation using a fuzzy logic speed controller, " Jordan Journal of Mechanical and Industrial Engineering, Vol. 8, No. 3, pp. 169-176, 2014.

[15] A. Belkheiri1, S. Aoughellanet, M. Belkheiri, « FPGA implementation of a space vector pulse width modulation technique for a two-level inverter, » Elektrotehniški Vestnik, Vol. 85, No. 3, pp. 1-7, 2018.

[16] B. Habib, Z. Boudjema, A. Belaidi, «Neuro-second order sliding mode control of a DFIG supplied by a two-level NSVM inverter for wind turbine system, » 
INTERNATIONAL JOURNAL Of SMART GRID

Habib Benbouhenni, Vol.2, No.4, December 2018

Iranian Journal of Electrical \& Electronic Engineering, In Press, 2018.

[17] B. Habib, Z. Boudjema, A. Belaidi, « Direct vector control of a DFIG supplied by an intelligent SVM inverter for wind turbine system, " Iranian Journal of Electrical \& Electronic Engineering, In Press, 2018.

[18] M. Hasni, Z. Mancer, S. Mekhtoub, S. Bacha, «Parametric identification of the doubly fed induction machine,» Energy Procedia, Vol. 18, pp. 177-186, 2012.

[19] E. Bounadja, A. Djahbar, Z. Boudjema, «Variable structure control of a doubly fed induction generator for wind energy conversion systems, » Energy Procedia, Vol. 50, pp. 999-1007, 2014.

[20] A. Medjber, A. Moualdia, A. Mellit, M. A. Guessoum, «Comparative study between direct and indirect vector control applied to a wind turbine equipped with a double-fed asynchronous machine article, » International Journal of Renewable Energy Research, Vol. 3, No. 1, pp. 88-93, 2013.

[21] K. Kerrouche, A. Mezouar, Kh. Belkacem, «Decoupled control of doubly fed induction generator by vector control for wind energy conversion system, »Energy Procedia, Vol. 42, pp. 239-248, 2013. 